\title{
Precise Measurement of Wavelengths in Infrared Spectra
}

\author{
Earle K. Plyler, Lamdin R. Blaine, and Eugene D. Tidwell
}

\begin{abstract}
The precise measurement of infrared absorption spectra has been accomplished by using the white-light fringes of a Fabry-Perot interferometer in conjunction with atomic spectral lines. Wavelengths from the first spectra of neon, argon, krypton, and xenon were used for calibrating the fringes. The absorption spectra and the fringe system are recorded simultaneously by a two-pen recorder. One pen records the higher orders of the fringe system of visible light as detected by a 1P28 photomultiplier. The other pen records the infrared absorption spectrum, which is detected by a $\mathrm{PbTe}$ cell. A measurement of the distance from the center of the absorption line to the neighboring maxima of the fringe system determines the line position to a high precision. Wavelengths of infrared lines can be measured with an error of one part in 500,000. Eight infrared lines of mercury, seventeen lines of krypton, and five lines of xenon have been measured by this method. Tables are given of visible and infrared lines of the noble gases, which are useful for calibration.
\end{abstract}

\section{Introduction}

While infrared spectra have been measured for the last 150 years, the precision of wavelength determination has been very low. The values given, up to 1900 , for the wavelengths of absorption bands were in error by about one part in a hundred. This low precision resulted from the small amounts of energy available for thermopiles, which made it necessary to use wide slits. Another contributing factor was the error introduced by the use of the indices of refraction, which were not known to a high precision for most prism materials. There was also the feeling that high precision optics was not necessary for infrared measurements. In 1917 Professor Randall [1] ${ }^{1}$ made measurements with gratings, and high resolution was obtained. In order to measure the rotational structure of bands, graduated circles were placed on the grating assembly, so that angles could be read to a few seconds of arc. This method of measurement, which was in use until about 4 years ago, greatly increased the accuracy and made it possible to measure sharp lines with an error of about one part in 10,000. More recently standard atomic lines have been used as a comparison spectrum. In the measurement of the $\mathrm{CO}$ band at $2.4 \mu$ [2] with a grating, higher orders of well known atomic lines of mercury, krypton, and xenon were superimposed on the absorption spectrum, and it found that the rotational lines could be measured with an error of one part in 100,000. The main drawback to this method of measurement is the fact that many lines are of low intensity, and they cannot be observed with narrow slits in the higher orders.

The next advance in the precise measurement of infrared spectra was the introduction of the FabryPerot interferometer. Douglas and Sharma [3] showed that, when illuminated with white light, the interferometer gave a series of fringes which were equally spaced, and these, therefore, offered an excellent comparison spectrum when calibrated with $\mathrm{Hg}^{198}$ standards. Channeled spectra of white light fringe systems have been used by several observers

Figures in brackets indicate the literature references at the end of this paper. in earlier investigations. Observed as early as 1850 by Fizeau and Foucault [4], the channeled spectrum was first used for measuring ultraviolet wavelengths by Esselback a century ago [5], and in 1879 Mouton [6] applied it to the measurement of invisible heat waves. However, no precise measurements could be made by this method until accurate standards of wavelength and improvements in spectrographs and radiation detectors became available. The use of the channeled spectrum provides very high precision in the relative measurements, but may be in error for the absolute values. The errors in the absolute measurements arise primarily from the condition that the fringe system is not transmitted along the optical axis of the instrument. The detector for the fringe system is a photomultiplier cell, and the optical path is different because it is necessary to place the photomultiplier behind the second slit. Small changes in the plane of the grating on scanning, or other changes, will alter the position of the maxima of the fringe system with respect to the absorption lines and thus will produce erratic absolute measurements.

A method of measurement which leads to high precision is to use noble gas spectra for calibrating. the fringe system of the Fabry-Perot interferometer, and then to use the fringe system as a comparison spectrum. A detailed description of this method of measurement is given in this paper.

\section{Experimental Method}

In order to make measurements of high precision, a grating spectrometer was used for the dispersing instrument. The grating, which is about 8 in. wide and 5 in. high, has rulings of 7,500 lines/in. The optical arrangement of the spectrometer [7] and of the radiation sources is shown in figure 1 . The source of radiation for the infrared measurements in the region from 1 to $3 \mu$ is a Western Union enclosed arc of $300-w$ capacity. The radiation source of the interferometer is a 100-w Western Union arc. The radiation sources for the standard wavelengths are Westinghouse enclosed ares which pass about 3 or 4 amp. The detector was a $\mathrm{PbTe}$ 


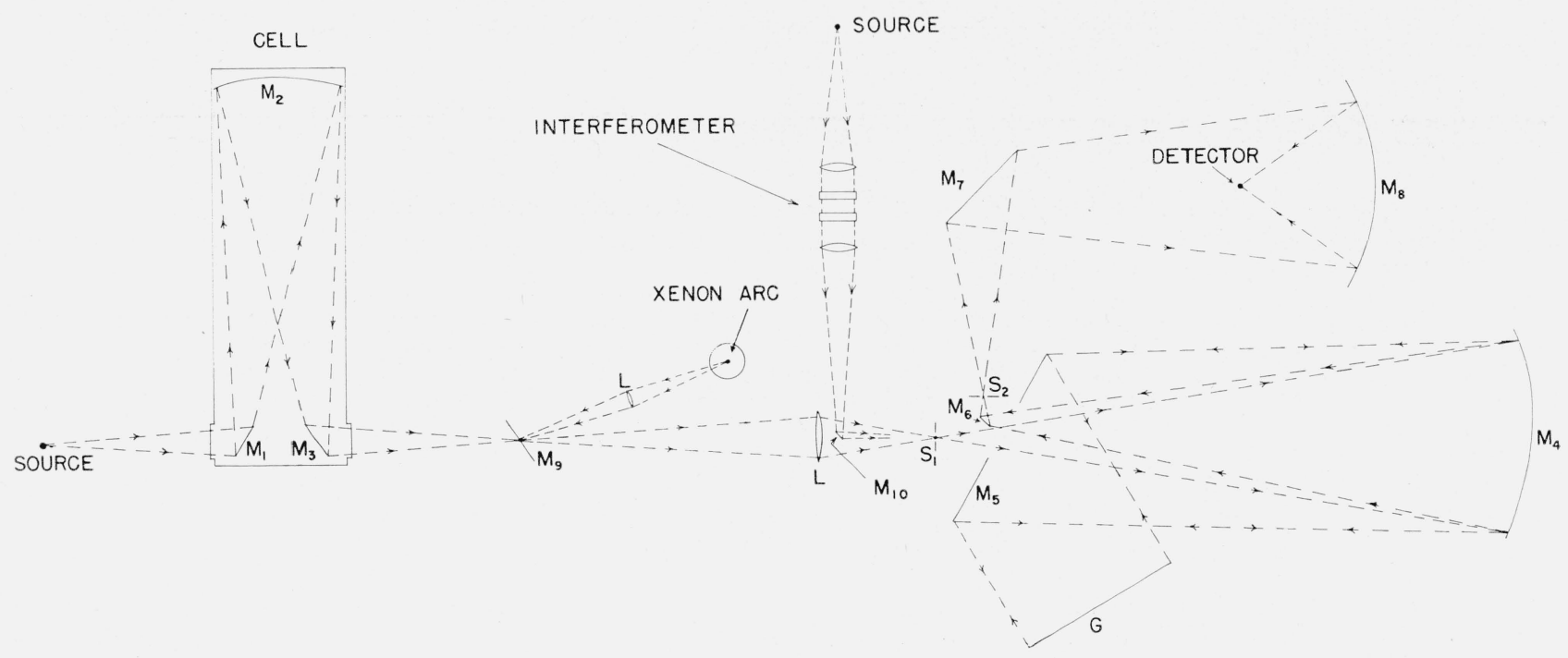

FIGURE 1. A diagram showing the optical arrangement of the spectrometer, the standard sources, and the interferometer.

cooled cell. The fringe system was detected by a 1 P28 photomultiplier which was placed behind the second slit. A small plane mirror was placed near the top of the second slit, and the radiation of the fringe system was reflected on the photomultiplier which was located above the slit. The small mirror covered about one fifth of the total slit, and the energy from the Nernst source or Western Union arc passed through the other part of the exit slit.

A detailed diagram of the Fabry-Perot inter ferometer is shown in figure 2. The two plates in the center are aluminized to about 50-percent transmission and are separated $2 \mathrm{~mm}$ by three invar pins. The maxima of the fringe system are separated about $0.3 \mathrm{~cm}^{-1}$ at $4.5 \mu$. The plates are held together by spring attachments, with pressure being applied directly in line with the three separators. The entire interferometer is placed within a vacuum cylinder to eliminate the effects of the index of refraction of air. In the ends are placed the lenses which collimate the light through the interferometer. The plates, separators, and spring attachments are assembled and attached to the cylinder head, where they can be removed as a single unit. The vacuum is held by means of an O-ring represented by two black dots in the figure. On using the Fabry-Perot interferometer in vacuum, it is possible to use silver reflecting surfaces on the plates rather than aluminum, since the silver will not tarnish.

Figure 3 shows the high orders of the emission lines of the krypton arc in the spectral region of 3.3 $\mu$. All the lines of good intensity have been identified, and they are useful in calibrating the spectrometer. If all of the regions of the spectrum have a sufficient number of limes at close intervals, they can be used as the calibrating spectrum without the interferometer. However, sufficient lines are not known in all regions, and the interferometer gives a more precise scale. In order to use a spectral line as a standard in the infrared region, its wave-

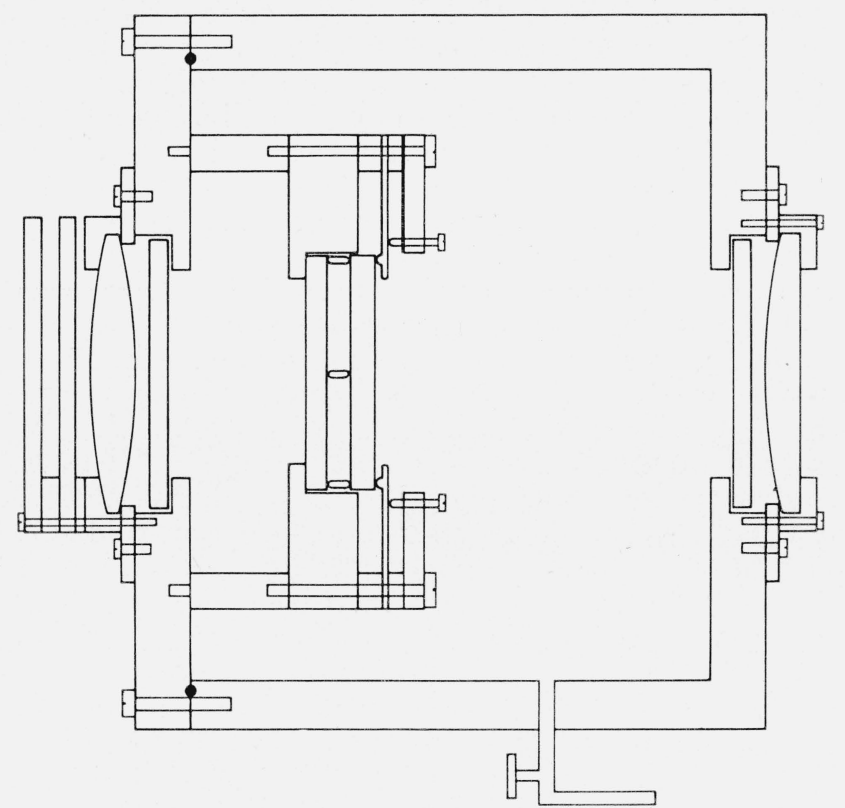

FIGURE 2. A diagram of a Fabry-Perot interferometer within. a vacuum system.

On the left is a holder for the standard filters.

length must be known to a high precision. Only the lines with wavelengths less than $1 \mu$ are known with such precision, and in order to use the lower wavelength lines of krypton in the 1-to $6-\mu$ region, it is necessary that they be observed in the higher orders. To provide a greater number of standard lines, many emission lines of krypton and xenon have been measured recently in the 1 -to $2-\mu$ regions. A table listing the wavelengths of these infrared lines, measured in this laboratory and useful as standards, will be given further in this paper (see table 4 ).

Figure 4 shows the interferometer fringes simultaneously recorded with the emission lines. This 


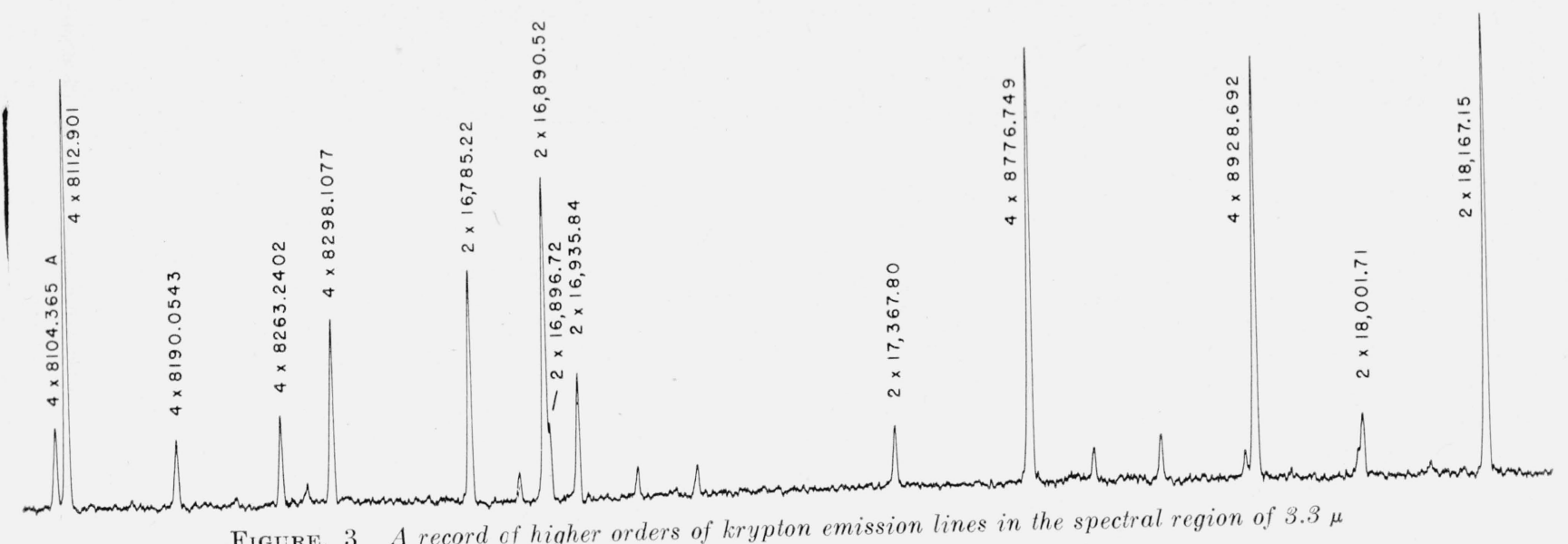

FIGURE. 3 A record of higher orders of krypton emission lines in the spectral region of $3.3 \mu$

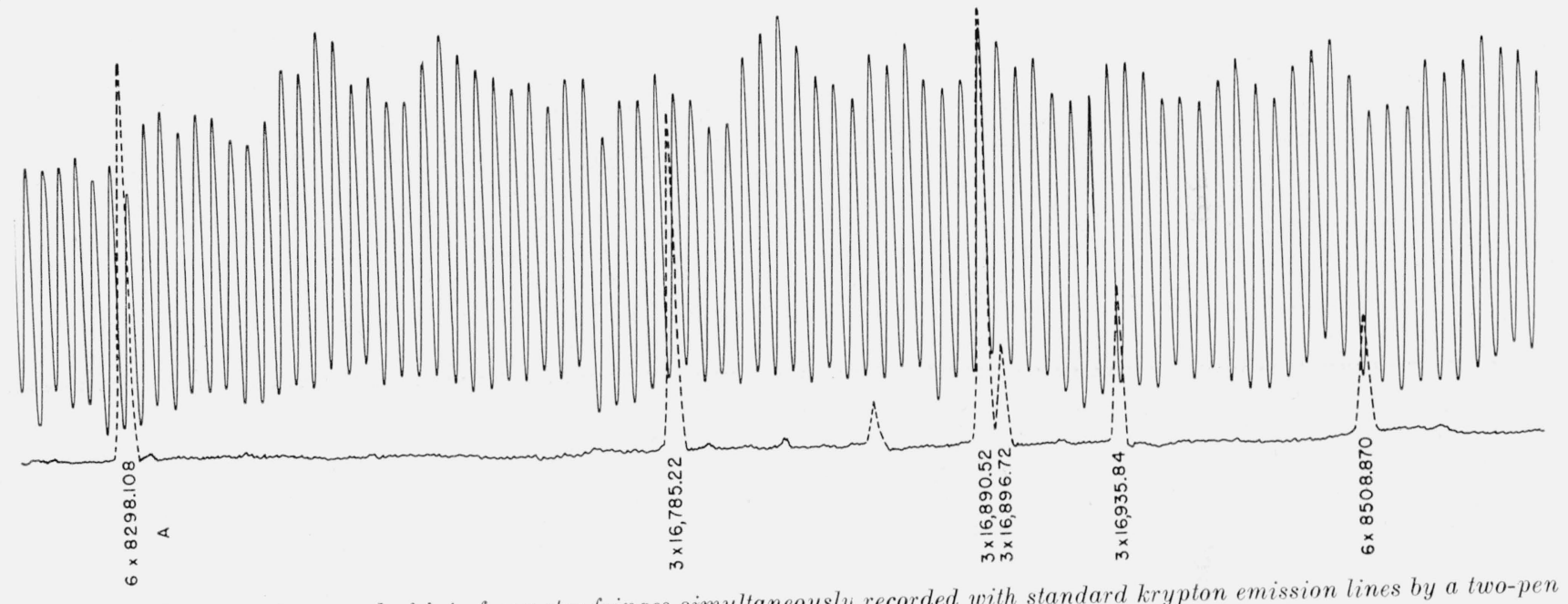

FIGURE 4. Tracing of a record of interferometer fringes simultaneous

record was made on a two-pen recorder, with one pen recording the fringe system as detected by a 1 P28 photomultiplier; the other pen records spectral lines as detected by a cooled $\mathrm{PbTe}$ cell.

For the record shown in figure 4, the mirror, M-9 (see fig. 1), has been thrown in position, so that the krypton lamp is being employed as a source. When the mirror, M-9, is removed, the absorption spectrum of the gas will be recorded by one pen, and the fringes of the interferometer will be recorded by the other pen. In the measurement of the absorption spectrum, at least two standard atomic lines are recorded, preferably one before the beginning and one at the end of the absorption band. The radiation from the krypton lamp travels along the same path as the radiation through the absorption cell, and in this way any shift of wavelengths between the two systems is avoided. The interferometer fringes are used as a comparison spectrum, and are given wavenumber values after being calibrated with the standard lines.

The fringes are formed of white light; consequently in the region from 1 to $6 \mu$, it is necessary to observe the fringes in higher orders. Table 1 is a list of Corning glass filters, with narrow bands of transmission, which are employed in conjunction with the 1P28 photomultiplier that has an upper limit of sensitivity of $0.62 \mu$. When a narrow range of the spectrum is desired, two filters can be used. For example, the transmission of Corning filters, 5543 and 3385 , extends over the spectral range of 0.47 to $0.51 \mu$. The cut-off ragion of the filters is sufficiently

TABLE 1. A list of Corning glass filters which are used with the interferometer

\begin{tabular}{|c|c|c|c|}
\hline Filter number & $\begin{array}{l}\text { Band width } \\
\text { in microns a }\end{array}$ & Filter number & $\begin{array}{l}\text { Band width } \\
\text { in microns a }\end{array}$ \\
\hline $\begin{array}{l}5970 \\
5031 \\
5030 \\
5562 \\
4303 \\
5543 \\
3389 \\
3387\end{array}$ & $\begin{array}{l}0.30 \text { to } 0.42 \\
.30 \text { to } .60 \\
.31 \text { to } .55 \\
.33 \text { to } .54 \\
.34 \text { to } .62 \\
.35 \text { to } .51 \\
.42 \text { to } .62 \\
.435 \text { to } .62\end{array}$ & $\begin{array}{l}3385 \\
3384 \\
\mathrm{X}-8 \\
3486 \\
3484 \\
3482 \\
2434 \\
3480 \\
2424\end{array}$ & 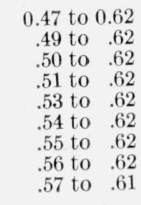 \\
\hline
\end{tabular}

The band width is determined by the filter and the long-wavelength cutof of the 1P28 photomultiplier. 


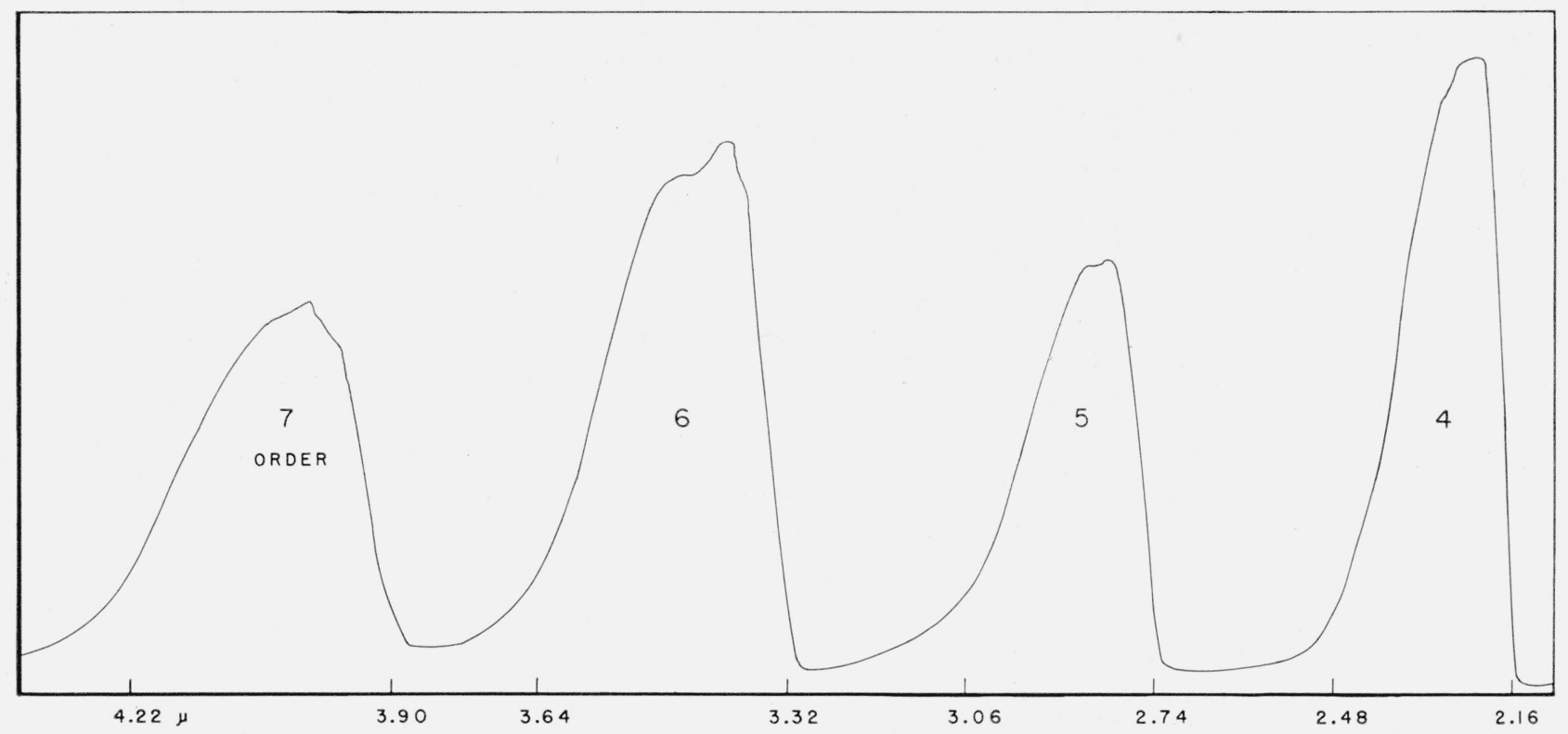

FiguRE 5. A portion of the unresolved fringe system showing the 4 th, 5th, 6th, and 7 th orders.

This fringe system is produced by white light in the spectral range from 0.54 to $0.62 \mu$.

sharp, so that there is no overlapping of different orders. From 1.5 to $1.8 \mu$, the third order of the visible fringes is used. This is done by employing Corning glass filter, $8 \mathrm{X}$, which begins transmitting at $0.5 \mu$; and since the detecting limit of 1 P28 photo cell is about $0.62 \mu$, this limits the band to 0.50 to $0.62 \mu$ in the first order or 1.50 to $1.86 \mu$ in the third order. At $6 \mu$ the 10 th or 11 th order of the visible fringes is used. To produce fringes which have a change between maxima and minima of 40 percent or better, it is sometimes necessary to shift the width of the fringe band with another filter or combination of filters.

Figure 5 shows four orders of unresolved fringe systems using Corning filter number 3482, which, in conjunction with the cutoff of the photomultiplier, transmits the spectral region from 0.54 to $0.62 \mu$. The intensity of the fringe system varies with the spectral order and the characteristics of the grating. Figure 5 is typical of a particular grating; the intensity of the orders will not have the same value for other gratings, but with the same set of filters, the maxima of the fringe system will occur at the same wavelengths for all gratings. All of the spectral region from 1 - to $6-\mu$ can be measured by observing the fringe system in different orders.

\section{Results}

To test the precision of the measurements, wellknown wavelengths of krypton lines have been measured in higher orders. The fringe system was calibrated by two known lines, and other lines were measured from the fringes. The atomic lines used as standards in these measurements are listed in table 2. The difference in wavenumbers between the two known lines is divided by the number of fringes between the two lines, thus giving a constant, the value of which depends on the spectral order of the fringe system. This constant is equal to the separation in wavenumbers between adjacent maxima of the fringe system, and is used to determine the wavenumber of any line. The distance of the atomic line from the neighboring maximum of the fringe system is determined by direct measurement to one hundreth of an inch. Table 2 shows the differences in measurements taken in this way compared with the published values [8] of these lines. The two sets of wavelengths check to about 1 part in 500,000 .

The infrared spectrum of mercury was explored more than 40 years ago by Paschen and by Volk [9]; the former reported 23 lines from 10140 to 40159 A and the latter 21 lines from 10140 to $23253 \mathrm{~A}$. The wavelengths of 22 lines between 13210 and $19200 \mathrm{~A}$

TABLE 2. A comparison of present measurements with known standards, Krypton

\begin{tabular}{|c|c|c|c|c|c|}
\hline $\begin{array}{l}\text { Meggers } \\
\text { and Hum- } \\
\text { phreys } \\
\text { 1st order }\end{array}$ & $\begin{array}{l}\text { Order } \\
\text { meas. }\end{array}$ & $\begin{array}{l}\text { Meggers } \\
\text { and Hum- } \\
\text { phreys }\end{array}$ & $\begin{array}{l}\text { Present } \\
\text { work }\end{array}$ & Difference & $\begin{array}{l}\text { Standards used } \\
\text { 1st order }\end{array}$ \\
\hline$\lambda$ Air & $n$ & $n \lambda \mathrm{Air}$ & $n \lambda$ Air & & \\
\hline$A$ & & $A$ & $A$ & $A$ & \multirow{9}{*}{ 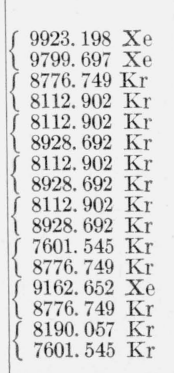 } \\
\hline 7601.545 & 4 & 30406.18 & 30406.31 & +0.13 & \\
\hline 8164.365 & 4 & 32417.46 & 32417.51 & +.05 & \\
\hline 8104.365 & 5 & 40521.83 & 40521.89 & +.07 & \\
\hline 8263.240 & 5 & 41316.20 & 41316.20 & .00 & \\
\hline 8776.749 & 5 & 43883.74 & 43883.73 & -.01 & \\
\hline 8928.692 & 4 & 35714.77 & 35714.68 & -.09 & \\
\hline 8928.692 & 6 & 53572.15 & 53572.31 & +.16 & \\
\hline 9751.759 & 5 & 48758.80 & 48758.96 & +.16 & \\
\hline
\end{tabular}


were recently refined by Humphreys [10]. Since the spectrum of mercury has many lines of high intensity in the region from 1 to $2 \mu$, it was thought desirable to survey the region from 2 to $5 \mu$ with the possibility of detecting other lines. In this region Paschen found 8 lines, and we have found 6 , only 2 of which are identifiable with his. The results of the present work are shown in table 3 . The wavelengths of four lines are in good agreement with the values calculated from the energy levels. The differences between the observed and calculated wavelengths are greater than the errors in the observed values. This difference may arise from the lack of interferometer values for the derivation of the "odd" energy levels in the transitions.

The third order of the line at $15295.63 \mathrm{~A}$ of mercury occured close to the first order line at $45122.04 \mathrm{~A}$. It was also measured and checked with the high resolution measurements of Humphreys, who found a value of $15295.82 \mathrm{~A}$.

The emission lines of neon, argon, krypton, and xenon are used for calibrating the fringe system. They are observed from Westinghouse enclosed arcs, operated on about 3 amp. Interferometric measurements on many of the lines of these gases have been made by Meggers and Humphreys [8]. The intense lines can be observed in the higher orders, and they have been used for calibration to $6 \mu$. In table 4 there are listed the more intense lines for each gas. The lines at wavelengths less than $10000 \mathrm{~A}$ have all been selected from the paper of Meggers and Humphreys.

The standards are only valid in standard air $\left(15^{\circ} \mathrm{C}\right.$ and $\left.760 \mathrm{~mm}\right)$. If measurements are made in air of different density serious errors can be introduced by multiplying uncorrected wavelengths by 4,5 , or 6 , if measured in the 4 th, 5 th or 6 th order, to get the "apparent" value in the infrared region. At the time the measurements on the krypton lines, reported in this work, were made, the temperature was $22^{\circ} \mathrm{C}$, and the pressure was $750 \mathrm{~mm}$. The correction for standard conditions to the wavelengths is of the order of $0.001 \mathrm{~A}$. If a line is used in the sixth order the correction would be $0.006 \mathrm{~A}$, and this value is about one-third the error in our observations. However, when values of highest precision are desired, the wavelengths of all lines should be reduced to standard conditions.

There are many intense lines of krypton and xenon between 1 and $2 \mu$, as shown by the exploratory

TABLE 3. Selected lines in the infrared spectrum of mercury

\begin{tabular}{|c|c|c|c|c|}
\hline \multicolumn{2}{|c|}{ Present work } & \multicolumn{2}{|c|}{$\begin{array}{l}\text { Calculated from } \\
\text { atomic energy levels }\end{array}$} & \multirow{2}{*}{ Designation } \\
\hline$\lambda$ Air & $\nu(\mathrm{vac})$ & $\lambda$ Air & $\nu(\mathrm{vac})$ & \\
\hline $\begin{array}{c}A \\
22493.28 \\
23253.07 \\
32148.06 \\
36303.03 \\
39283.61 \\
45122.04\end{array}$ & $\begin{array}{c}C M^{-1} \\
\text { a } 4444.56 \pm 0.01 \\
4299.33 \pm 0.02 \\
3109.76 \pm 0.02 \\
2753.84 \pm 0.002 \\
2544.90 \pm 0.042 \\
2215.63 \pm 0.027\end{array}$ & $\begin{array}{c}A \\
22492.85 \\
23252.63 \\
32151.32 \\
36303.78 \\
\end{array}$ & $\begin{array}{c}C M^{-1} \\
4444.64 \\
4299.41 \\
3109.44 \\
2753.79 \\
\end{array}$ &  \\
\hline
\end{tabular}

\& The average deviation of six measurements. work of Humphreys and Plyler [11], of Sittner and Peck [12], and of Humphreys and Kostkowski [13]. These lines have not been measured with an interferometer and, therefore, could not be used as standards. Some of these lines have been measured in the present work and are also listed in table 4 . Some gratings have low intensities in certain orders, and by having additional standard lines available from 1 to $2 \mu$, it is possible to measure in the entire region from 1 to $6 \mu$.

It would be desirable to have many standards in the infrared region, and certain lines should be measured by the interferometer directly, as has been done in the visible and near infrared regions. The method of measurement in the infrared region would be similar to that used in the photographic

TABLE 4. A list of intense atomic lines of neon, argon, krypton, and xenon for infrared calibration

\begin{tabular}{|c|c|c|c|c|}
\hline \multicolumn{5}{|c|}{ NEON } \\
\hline$\lambda$ in air & $\lambda$ in air & $\lambda$ in air & $\lambda$ in air & $\lambda$ in air \\
\hline \begin{tabular}{l}
\multicolumn{1}{c}{$A$} \\
4422.519 \\
4424.800 \\
4488.0928 \\
4537.68 \\
4537.751
\end{tabular} & \begin{tabular}{l}
\multicolumn{1}{c}{$A$} \\
4827.587 \\
4837.3118 \\
4884.915 \\
4892.090 \\
4957.0334
\end{tabular} & \begin{tabular}{l}
\multicolumn{1}{c}{$A$} \\
5820.148 \\
5852.4880 \\
5881.8950 \\
5944.8343 \\
5965.474
\end{tabular} & $\begin{array}{c}\text { A } \\
6678.2766 \\
6929.4678 \\
7024.0508 \\
7032.4134 \\
7173.9389\end{array}$ & \begin{tabular}{l}
\multicolumn{1}{c}{$A$} \\
8679.491 \\
8681.920 \\
8771.70 \\
8780.6223 \\
8783.755
\end{tabular} \\
\hline $\begin{array}{l}4538.31 \\
4575.060 \\
4645.416 \\
4656.3923 \\
4678.218\end{array}$ & $\begin{array}{l}\text { 5005. } 160 \\
5037.7505 \\
5144.9376 \\
5145.01 \\
5330.7766\end{array}$ & $\begin{array}{l}5974.628 \\
5975.5339 \\
6029.9970 \\
6074.3377 \\
6096.1630\end{array}$ & $\begin{array}{l}7245.1668 \\
7438.8990 \\
7488.8722 \\
7535.7750 \\
7943.1802\end{array}$ & $\begin{array}{l}8853.867 \\
8865.759 \\
8919.50 \\
9148.68 \\
9201.76\end{array}$ \\
\hline $\begin{array}{l}4704.395 \\
4708.854 \\
4712.06 \\
4715.344 \\
4749.572\end{array}$ & $\begin{array}{l}5341.091 \\
5343.284 \\
5400.5620 \\
5562.769 \\
5656.6585\end{array}$ & $\begin{array}{l}6143.0624 \\
6163.5937 \\
6217.2811 \\
6266.4950 \\
6304.7893\end{array}$ & $\begin{array}{l}8082.4580 \\
8136.4060 \\
8266.076 \\
8300.3258 \\
8377.6068\end{array}$ & $\begin{array}{l}9220.05 \\
9300.85 \\
9313.98 \\
9326.52 \\
9425.38\end{array}$ \\
\hline $\begin{array}{l}4752.7313 \\
4788.9258 \\
4817.636 \\
4821.924 \\
4827.338\end{array}$ & $\begin{array}{l}\text { 5719. } 2254 \\
5748.299 \\
5764.4182 \\
5804.4488 \\
5811.42\end{array}$ & $\begin{array}{l}6334.4280 \\
6382.9914 \\
6402.2455 \\
6506.5278 \\
6598.9528\end{array}$ & $\begin{array}{l}8418.4274 \\
8495.3600 \\
8591.2584 \\
8634.6480 \\
8654.3835\end{array}$ & $\begin{array}{l}9459.21 \\
9486.680 \\
9535.167 \\
9547.40 \\
9665.424\end{array}$ \\
\hline \multicolumn{5}{|c|}{$A R G O N$} \\
\hline $\begin{array}{l}6965.4302 \\
7030.262 \\
7067.2170 \\
7147.0406 \\
7272.9357\end{array}$ & $\begin{array}{l}7383.9800 \\
7503.8676 \\
7514.6510 \\
7635.1053 \\
7723.7597\end{array}$ & $\begin{array}{l}7891.075 \\
7948.1754 \\
8006.1556 \\
8014.7856 \\
8053.307\end{array}$ & $\begin{array}{l}8115.3115 \\
8264.5209 \\
8408.208 \\
8424.647 \\
8521.4407\end{array}$ & $\begin{array}{l}9122.9660 \\
9224.498 \\
9354.218 \\
9657.7841 \\
9784.5010\end{array}$ \\
\hline 7372.117 & 7724. 2064 & 8103.6922 & 8667.9430 & 10470.051 \\
\hline \multicolumn{5}{|c|}{ KRYPTON } \\
\hline $\begin{array}{l}7486.862 \\
7587.4130 \\
7601.5443 \\
7685.2460 \\
7694.5395\end{array}$ & $\begin{array}{l}8104.3642 \\
8112.902 \\
8190.0543 \\
8263.2398 \\
8281.0495\end{array}$ & $\begin{aligned} & 8776.7490 \\
& 8928.6920 \\
& 9751.759 \\
& \text { a } 13634.28 \\
& \text { a } 13738.94\end{aligned}$ & $\begin{array}{l}\text { a } 14347.69 \\
\text { a } 14426.67 \\
\text { a } 14734.42 \\
\text { a } 15239.67 \\
\text { a } 15334.92\end{array}$ & $\begin{array}{l}\text { a } 16896.72 \\
\text { a } 16935.84 \\
\text { a } 17367.80 \\
\text { a } 18001.71 \\
\text { a } 18167.15\end{array}$ \\
\hline $\begin{array}{l}7854.8217 \\
8059.5038\end{array}$ & $\begin{array}{l}8298.1077 \\
8508.8700\end{array}$ & $\begin{array}{l}\text { a } 13883.15 \\
\text { a } 13924.11\end{array}$ & $\begin{array}{l}\text { a } 16785.22 \\
\text { a } 16890.52\end{array}$ & a 21902.51 \\
\hline \multicolumn{5}{|c|}{ XENON } \\
\hline $\begin{array}{l}7119.598 \\
7285.301 \\
7312.452 \\
7316.272 \\
7386.003\end{array}$ & $\begin{array}{l}7643.91 \\
7802.651 \\
7881.320 \\
7887.3898 \\
7967.342\end{array}$ & $\begin{array}{l}8231.6336 \\
8280.1162 \\
8346.8217 \\
8409.1894 \\
8648.54\end{array}$ & $\begin{array}{l}8908.73 \\
8930.83 \\
8952.2506 \\
8987.57 \\
9045.4460\end{array}$ & $\begin{aligned} & 9799.697 \\
& 9923.198 \\
& \text { a } 12623.36 \\
& \text { a } 13657.22 \\
& \text { a } 14241.23\end{aligned}$ \\
\hline $\begin{array}{l}7393.793 \\
7584.680 \\
7642.025\end{array}$ & $\begin{array}{l}8057.258 \\
8061.339 \\
8206.336\end{array}$ & $\begin{array}{l}8739.372 \\
8819.411 \\
8862.32\end{array}$ & $\begin{array}{l}9162.6520 \\
9374.76 \\
9513.377\end{array}$ & $\begin{array}{l}\text { a } 14732.88 \\
\text { a } 15418.12\end{array}$ \\
\hline
\end{tabular}

a Measured in present work 
region, except that a semiconductor cell would be employed to scan the Haidinger fringe pattern.

The authors wish to express their appreciation to Dr. W. F. Meggers and Mrs. C. M. Sitterly of the Spectroscopy Section for helpful suggestions with regard to these measurements.

\section{References}

[1] H. M. Randall and E. F. Imes, Phys. Rev. 15, 152 (1920).

[2] Earle K. Plyler, W. S. Benedict, and Shirleigh Silverman, J. Chem. Phys. 20, 175 (1953).

[3] A. E. Douglas and D. Sharma, J. Chem. Phys. 21, 448 (1953).

[4] H. Fizeau and L. Foucault, Ann. chim. et phys. (3) 30, $146(1850)$.
[5] E. Esselback, Ann. der Physik und Chemie 98, 513 (1856).

[6] M. L. Mouton, J. Phys. (1) 8, 393 (1879).

[7] Plyler, Blaine, and Connor, J. Opt. Soc. Amer. 45, 103 (1955).

[8] William F. Meggers and C. J. Humphreys, J. Research NBS, 13, 292 (1934) RP710.

[9] F. Paschen and C. Volk, H. Kayser, and H. Konen, Handbuch der Spectroscopie 7,669 (1934).

[10] J. Humphreys, J. Opt Soc. Amer. 43, 1027 (1953).

[11] C. J. Humphreys and Earle K. Plyler, J. Research NBS 38, 499 (1947) RP1790.

[12] W. R. Sittner and E. R. Peck, J. Opt Soc. Amer, 39, 474 (1949).

[13] C. J. Humphreys and Henry Kostkowski, J. Research NBS 49, 73 (1952) RP2345.

Washington, June 14,1955 